\title{
Thermal Evaluation of Natural Convection in a Ventilated Roof under Variable Climatic Condition
}

\author{
Bernardo Buonomo, Lucia Capasso, Oronzio Manca*, Sergio Nardini, Marina Pennacchio \\ Dipartimento di Ingegneria, Università degli Studi della Campania “Luigi Vanvitelli”, Via Roma 29, 81031 Aversa, Italy
}

Corresponding Author Email: oronzio.manca@unicampania.it

https://doi.org/10.18280/ti-ijes.642-436

Received: 12 February 2020

Accepted: 17 May 2020

\section{Keywords:}

ventilated roof, numerical investigation, summer and winter conditions, energy saving, heat transfer model, solar heat flux

\begin{abstract}
One of the European Directive priorities is represented by the improvement of "building performance requirements" and the development of new strategies for "very low energy buildings" thanks to it is possible to reduce the energy consumptions due to the heat flux transmitted through the envelope of buildings. This paper illustrates a numerical investigation on a system that made possible this goal, in the specific a prototypal ventilated roof for residential use, inclined of $15^{\circ}$ respect to the horizontal plane and the results are compared with a configuration with an inclination of $30^{\circ}$. Due to geometric and thermal symmetry the system has been studied considering a single side of the pitched roof. The analysis is carried out on a two-dimensional model in air flow and the governing equations are given in terms of k- $\varepsilon$ turbulence model. The investigation is performed to evaluate thermo fluid dynamic behaviors of the ventilated roof as a function of the different conditions applied on the top wall and the bottom wall of the roof in summer and winter regimes. The problem is solved by means of the commercial code Ansys-Fluent on a channel of $6 \mathrm{~m}$ of length. The comparison shows that the inclination of $30^{\circ}$ is more convenient both in summer and in winter due to the higher mass flow rate inside the channel.
\end{abstract}

\section{INTRODUCTION}

The worldwide attention for the safety of the environment has made energy savings in buildings a focal factor, resulting in the promotion of environmentally friendly solutions, using technologies designed for keeping constant temperatures inside buildings and to limit the energy usage. The most important passive solution for temperature and humidity comfort inside structures is the ventilated roof technology, which is aimed at keeping constant indoor temperature with limited energy consumption, whilst also increasing the useful life of the roof structures, by protecting them from humidity and mold.

When heating the covering exposed to the sun, the air increases in volume and decreases in weight and moves to the top of the roof and then escapes from the roof ridge, then causing the suction of fresh air from the gutter. This gradually removes the heat that develops on the roof covering, preventing it from travelling through the building.

In winter, due to the air circulation, the insulation will be always ventilated, and therefore dry and for these reasons there won't be inner condensation, so the performance, quality and functionality of the roof are preserved.

Typically, the ventilated roof presents five principal components [1]:

Roof cover: the outermost, it represents an effective barrier against the action of the rain and the capillary.

Layer ventilation: It is placed immediately under the mantle. It consists of a cavity which allows to the air to flow along the channel for the entire length of the roof.

Layer of thermal insulation: It consists of one or more types of panels of insulating material.
- Waterproofing: It prevents infiltration of rainwater and percolation of condensation thanks to waterproof concrete. Structure: It supports permanent and accidental loads. It must withstand exceptional events such as severe storms and earthquakes.

Due to importance of this argument, a lot of studies were made in the course of the years. In [2] the authors have analyzed the thermal behavior of ventilated roofs with same value of thermal resistance but different distribution of the thermal layer insulation respect to the air opening, demonstrating that this technology can reduce of almost $50 \%$ the heat transfer between roof-construction.

For residential buildings in Northeast China [3] was also numerically investigates the effect of different parameters on thermal behavior of ventilated roof, such as ventilated air gap thickness, roof slope, exhaust outlet size and absorption coefficients of external roof surface.

Numerical analyses were made to understand the consequence of variable solar radiation in summer and winter [4]; during specific day in summer [5] to evaluate the performance of pitched roof with tiled coverings in comparison with unventilated systems and the results show that wind plays an important role. Compared to the tiles, both numerical and experimental analysis [6] were done in order to investigate the properties and the impact that clay tile materials have on the thermal performance of a ventilated roof. Due to problem of interstitial condensation in flat roofs, some authors [7] provide a method for evaluating the ventilation air flow rates necessary to avoid it and this is possible with small size fans with low energy consumptions, the efficacy of using this device was also demonstrated by small scale experiments [8].

As alternative to a fan it could be possible change geometry 
of the roof, in fact laboratory measurements were conducted [9] that show how temperature and flow conditions in the air cavity are dependent on cavity height and roof inclination. This last parameter was analyzed also in case of different weather conditions in India [10], particularly during winter, summer, and monsoon seasons, but the results show that the roof inclination is not enough to guarantee the human comfort condition.

This paper presents a numerical investigation on the effect of inclination angle of a prototypal ventilated roof for residential use, in order to evaluate thermo fluid-dynamic behaviors of it. The analysis is carried out on a twodimensional model in air flow and the governing equations are given in terms of $\mathrm{k}-\varepsilon$ turbulence model. The problem is solved by means of the commercial code Ansys-Fluent. Results are given in terms of temperature and pressure distributions, air velocity and temperature profiles along different sections of the ventilated channel to estimate the differences between the various conditions.

\section{MATHEMATICAL MODEL}

The physical domain under investigation, reported in Figure 1 , is two-dimensional and due to geometric and thermal symmetry the system has been studied considering a single side of the pitched roof. The computational domain is shown in Figure 2, it has finite dimensions, reported in Table 1, and it is composed by the ventilated channel and two storages located at the inlet and the outlet of the channel. Thanks to that it is possible to understand what happens near the section of the thermal disturbance produced by the heat applied on the upper of the cavity to simulate the free-stream condition of the flow.
Table 1. Dimensions of the computational domain

\begin{tabular}{cc}
\hline Dimension & {$[\mathbf{m}]$} \\
\hline $\mathrm{L}$ & 6.00 \\
\hline $\mathrm{L}_{\mathrm{x}}=\mathrm{L}_{\mathrm{y}}$ & 3.00 \\
\hline $\mathrm{b}$ & 0.10 \\
\hline $\mathrm{h}$ & 0.10 \\
\hline$\theta$ & $15^{\circ}$ \\
\hline
\end{tabular}

The assumption made for the channel are to consider a 2D flow, a steady-state turbulent regime, negligible viscous dissipations and thermophysical properties constant with temperature, except for the density, which produces buoyancy forces, for which the Boussinesq's approximation was made. The governing equations can be written as:

Mass conservation

$$
\frac{\partial \rho}{\partial t}+\rho \bar{\nabla} \cdot \bar{V}=0
$$

Momentum equation

$$
\begin{aligned}
& \rho \frac{D u}{D t}=\rho f_{x}-\frac{\partial p}{\partial x}+\frac{\partial \tau_{x x}}{\partial x}+\frac{\partial \tau_{y x}}{\partial y} \\
& \rho \frac{D v}{D t}=\rho f_{y}-\frac{\partial p}{\partial y}+\frac{\partial \tau_{x y}}{\partial x}+\frac{\partial \tau_{y y}}{\partial y}
\end{aligned}
$$

Energy conservation

$$
\rho c_{p} \frac{D T}{D t}=k \nabla^{2} T+\mu_{t} \Phi+u^{\prime \prime \prime}
$$

With $\mu_{\mathrm{t}}$ turbulent dynamic viscosity calculated from the knowledge of the kinetic energy of turbulence, k Eq. (6), and turbulent kinetic energy dissipation rate, $\varepsilon$ Eq. (7),

$$
\mu_{t}=\rho \cdot C_{\mu} \cdot f_{\mu} \cdot\left(\frac{k^{2}}{\varepsilon}\right)
$$

Turbulence kinetic energy (k-equation)

$$
\begin{aligned}
& \frac{\partial}{\partial x}(\rho \overline{u k})+\frac{\partial}{\partial y}(\rho \bar{v} k)=\frac{\partial}{\partial x}\left[\left(\mu+\frac{\mu_{t}}{\sigma_{k}}\right) \frac{\partial k}{\partial x}\right]+ \\
& \frac{\partial}{\partial y}\left[\left(\mu+\frac{\mu_{t}}{\sigma_{k}}\right) \frac{\partial k}{\partial y}\right]+G_{k}+G_{b}-\rho \varepsilon-D
\end{aligned}
$$

Turbulence dissipation ( $\varepsilon$-equation)

$$
\begin{aligned}
& \frac{\partial}{\partial x}(\rho \bar{u} \varepsilon)+\frac{\partial}{\partial y}(\rho \bar{v} \varepsilon)=\frac{\partial}{\partial x}\left[\left(\mu+\frac{\mu_{t}}{\sigma_{\varepsilon}}\right) \frac{\partial \varepsilon}{\partial x}\right] \\
& +\frac{\partial}{\partial y}\left[\left(\mu+\frac{\mu_{t}}{\sigma_{\varepsilon}}\right) \frac{\partial \varepsilon}{\partial y}\right]+C_{\varepsilon 1} f_{1} \frac{\varepsilon}{k}\left(G_{k}+G_{\varepsilon 3} G_{b}\right) \\
& -C_{\varepsilon 2} f_{2} \frac{\varepsilon^{2}}{k}+E
\end{aligned}
$$

Figure 2. Computational domain 
In the $k-\varepsilon$ Eqns. (7) and (8) [11], the first two terms represent the kinetic energy transport of turbulence and the dissipation kinetic energy rate by convection. Third and fourth terms represent transport of these quantities by diffusion. $G_{k}$ $\left(\left(\rho \overline{u_{i}^{\prime} u_{j}^{\prime}}\right)\left(\partial u_{j} / \partial x_{i}\right)\right)$ represents the rate of generation of turbulent kinetic energy due to mean velocity gradients, $\rho \varepsilon$ is the destruction rate of the turbulent kinetic energy and $G_{b}$ $\left(\beta g_{i}\left(\mu_{t} / P r_{t}\right)\left(\partial T / \partial x_{i}\right)\right)$ is the rate of generation of turbulent kinetic due to buoyancy. Terms symbolized by $D$ in $k$-equation and $E$ in $\varepsilon$-equation are used to consider the behavior near the wall; $f_{1}$ and $f_{2}$ are the wall damping functions in $\varepsilon$-equation.

The Surface-to-Surface radiation model (S2S) was chosen. The convergence criteria of $10^{-6}$ for the residuals of the velocity components and of $10^{-8}$ for the residuals of the energy were assumed.

\section{NUMERICAL SOLUTION}

The thermophysical analysis presented in this document is characterized by coupled, non-linear, partial differential governing equations which are solved with finite volume method implemented in the commercial code Ansys Fluent [12]. The numerical model simulated is an inclined channel, with the upper and the bottom lines simulating respectively the properties of all layers above and under the ventilated channel. In this work, summer and winter regims are studied with the following operating conditions:

- Summer: operative temperature equal to $300 \mathrm{~K}$, bottom wall of the ventilated cavity is considered isothermal with $\mathrm{T}=298 \mathrm{~K}$.

- Winter: bottom wall of the ventilated cavity is considered isothermal with $\mathrm{T}=293 \mathrm{~K}$.

In both cases a uniform heat flux on the top wall of the channel is applied, considering 3 hours $(9: 00,12: 00,15: 00)$ of a typical summer and winter day (Table 2 ).

Values of heat flux are obteined by the PVGIS database [13]. Furthermore, the bottom wall and the top wall of the ventilated channel simulate the properties of structure layers under the cavity and of structure layers above the cavity, respectively.

Table 2. Heat flux values

\begin{tabular}{ccc}
\hline Time $[\mathbf{h}]$ & $\mathbf{q s}_{\mathbf{s}}\left[\mathbf{W} / \mathbf{m}^{\mathbf{2}}\right]$ & $\mathbf{q}_{\mathbf{w}}\left[\mathbf{W} / \mathbf{m}^{\mathbf{2}}\right]$ \\
\hline $9: 00$ & 774 & 331 \\
\hline $12: 00$ & 888 & 409 \\
\hline $15: 00$ & 493 & 101 \\
\hline
\end{tabular}

The geometric model and the mesh of the computational domain are realized with the software Gambit [14]. As the choice of mesh is a compromise between the calculation time and the quality of the solution, it is important to evaluate a sensitivity of the mesh so three type of grid calculation was evaluated (Table 3). Along specific characteristic sections of the domain a values evaluation of temperature (Figure 3) was made and the obtained results demonstrate that the mesh2 represents the best choice.

Table 3. Analyzed grids

\begin{tabular}{cc}
\hline Mesh & Calculation cells \\
\hline 1 & 21162 \\
\hline 2 & 39402 \\
\hline 3 & 62202 \\
\hline
\end{tabular}

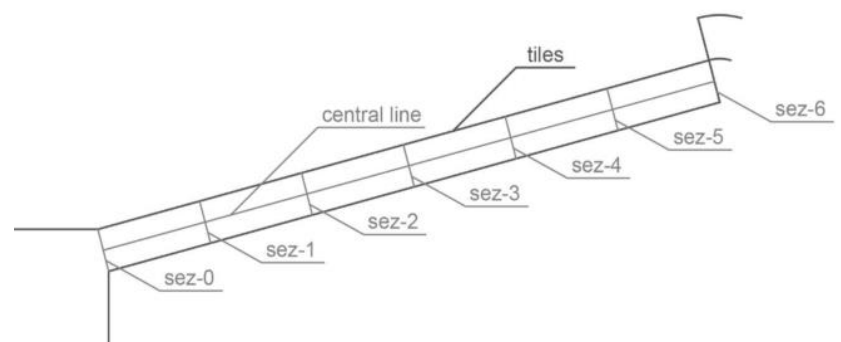

(a) Channel sections

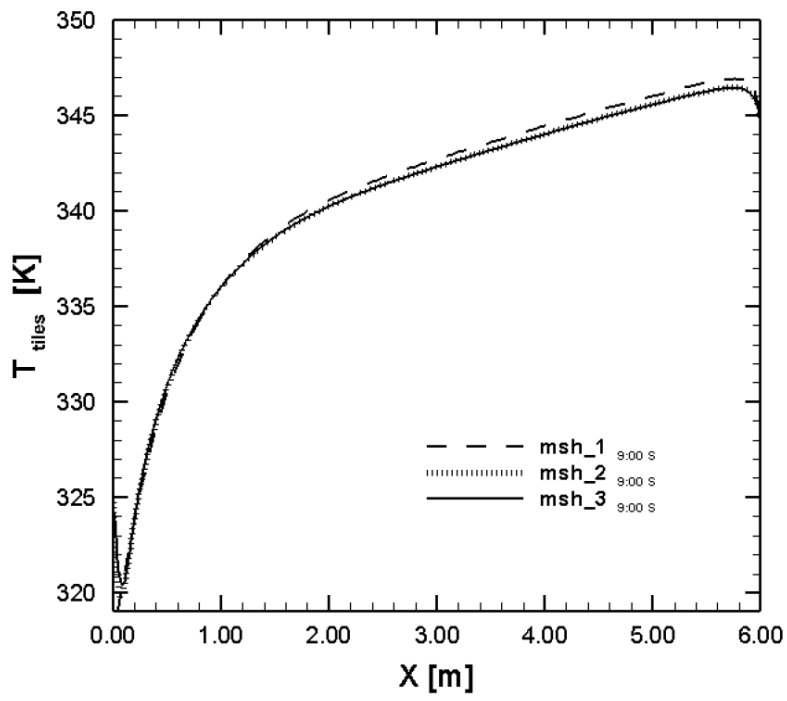

(b) Tiles temperature profile

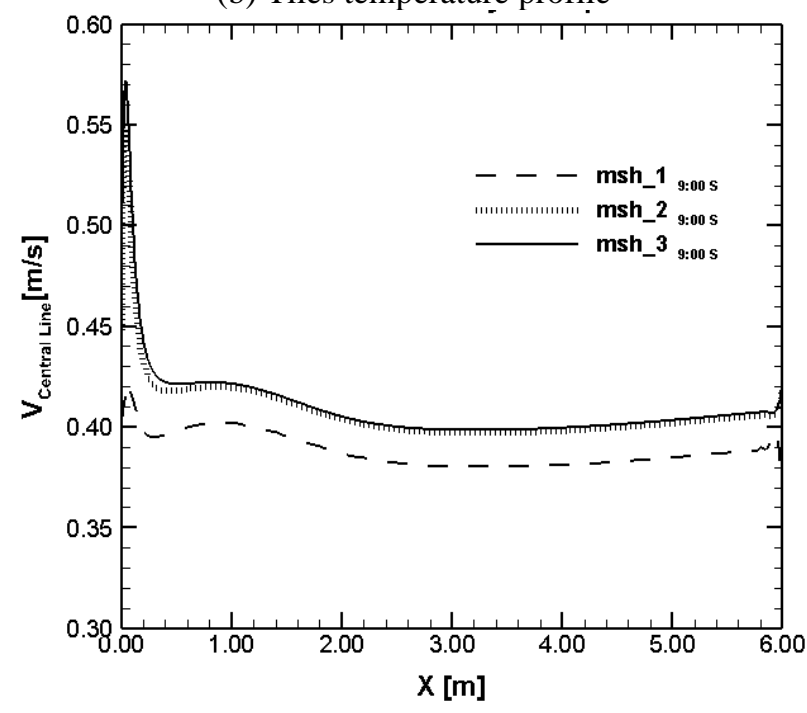

(c) Central line velocity profile

Figure 3. Evaluated values (b), (c) along specific sections (a)

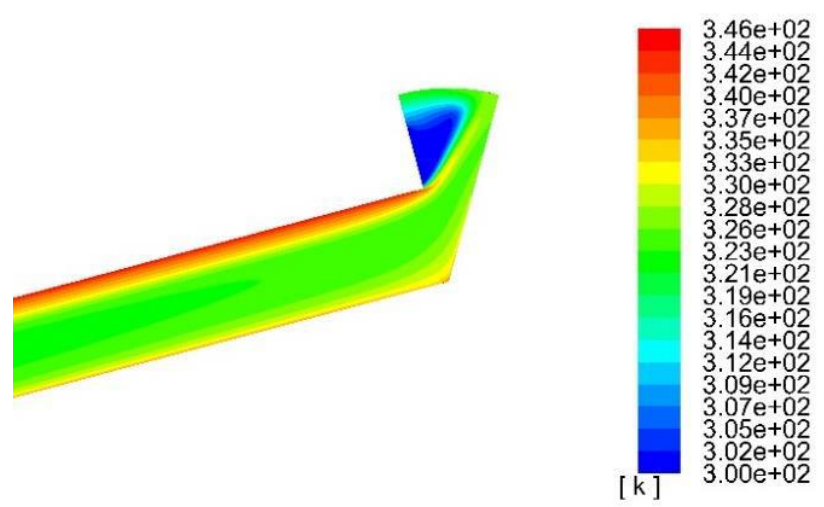

(a) Temperature field at 9:00 


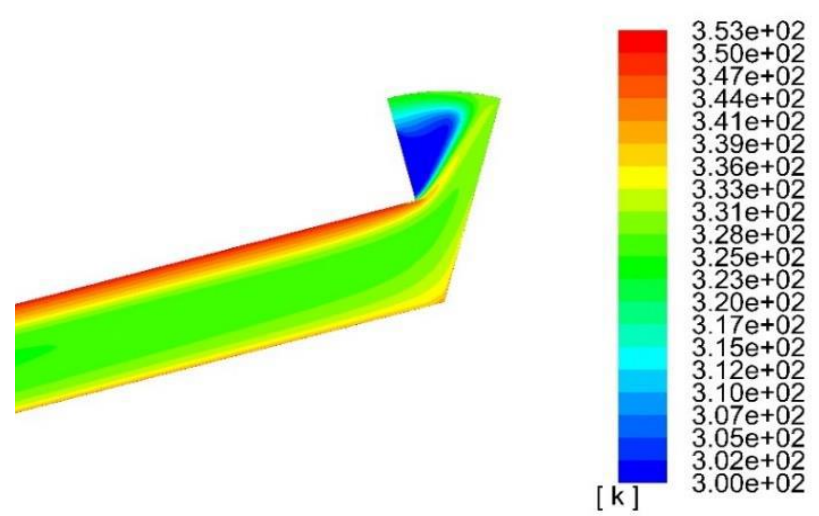

(b) Temperature field at 12:00
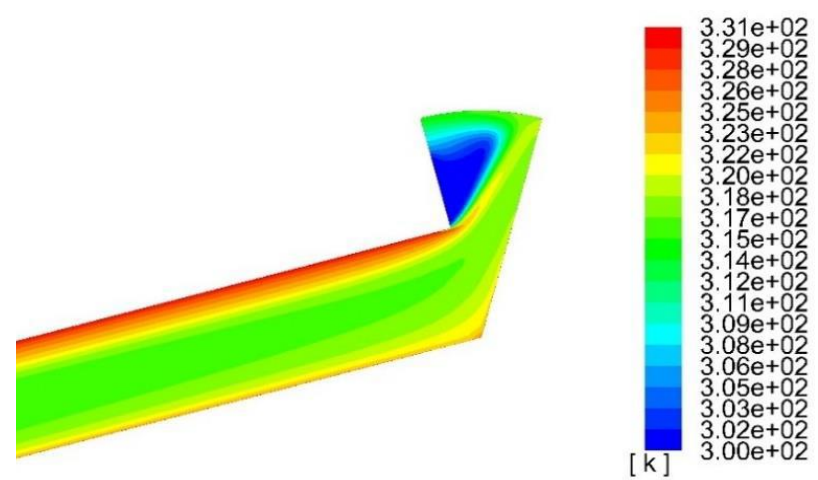

(c) Temperature field at 15:00

Figure 4. Summer air temperature fields at the end of the channel

\section{RESULTS AND DISCUSSION}

In this work a study on thermo-fluid dynamic behaviors of a ventilated roof (which thermophysical characteristics of the material are reported in Table 4) inclined of $15^{\circ}$ respect to the horizontal line, in summer and winter conditions, was presented. As depicted in the Figures 4 and 5, the temperature of the air inside the ventilated channel reaches highest values of $353 \mathrm{~K}$, in summer, and $322 \mathrm{~K}$, in winter, at 12:00 near the upper boundary layer of the cavity.

These values can be found in the temperature profiles, Figure 6(a) and (b). In fact, the temperature evaluated along the central line of the cavity increases near the outlet section of it and this value is the higher when the thermal flow resulting from the growth of the radiation increases. Peak values are equal to $325 \mathrm{~K}$ at the 9:00, $327 \mathrm{~K}$ at the $12: 00$ and $317 \mathrm{~K}$ at 15:00 in the summer case and equal to $310 \mathrm{~K}$ at the 9:00, $313 \mathrm{~K}$ at the $12: 00$ and $311 \mathrm{~K}$ at 15:00 in the winter case.

From the profiles of the temperatures inside the channel, along the transversal sections, situated at $1 \mathrm{~m}$ (sez-1), $2 \mathrm{~m}$ (sez2), $3 \mathrm{~m}$ (sez-3), $4 \mathrm{~m}$ (sez-4) and $5 \mathrm{~m}$ (sez-5)from the beginning of the channel, Figure 7(a) and (b), it is possible to note that the difference in its values is more significant in summer case respect to the winter case, in fact in the first case the range of values are equal to 304-323 K during the summer and to $302-$ $311 \mathrm{~K}$ during the winter.

About the velocity, the analysis made on the central line, Figure 8 (a) and (b) of the ventilated channel shows an important decrease of the profile after the inlet section, hence the values are almost constant in both summer and winter cases.
The highest values of velocity are equal to $0.54 \mathrm{~m} / \mathrm{s}, 0.56$ $\mathrm{m} / \mathrm{s}$ and to $0.43 \mathrm{~m} / \mathrm{s}$ at the 9:00, 12:00 and 15:00, respectively, in the summer configuration, and are equal to $0.35 \mathrm{~m} / \mathrm{s}, 0.39$ $\mathrm{m} / \mathrm{s}$ and $0.10 \mathrm{~m} / \mathrm{s}$ at the 9:00, 12:00 and 15:00, respectively, in the winter configuration.

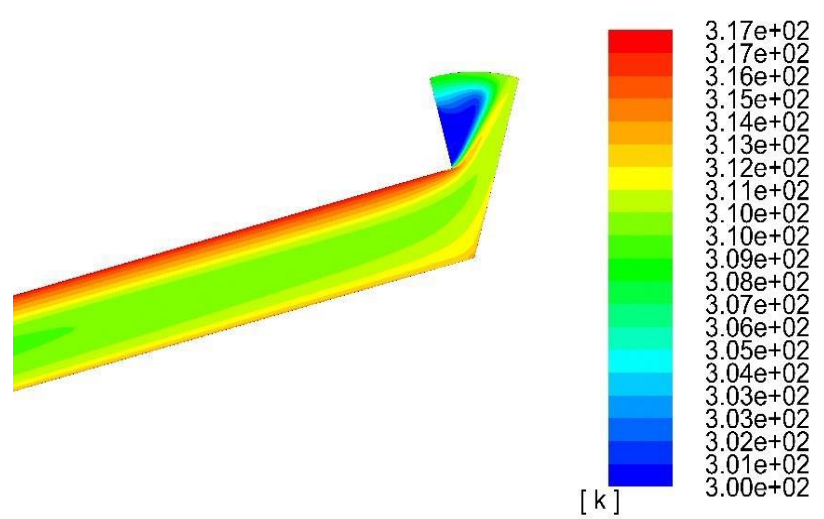

(a) Temperature field at 9:00

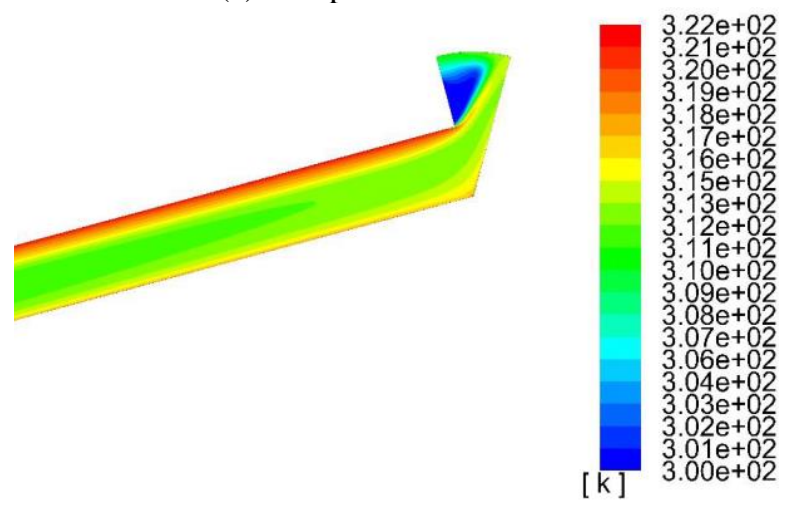

(b) Temperature field at 12:00

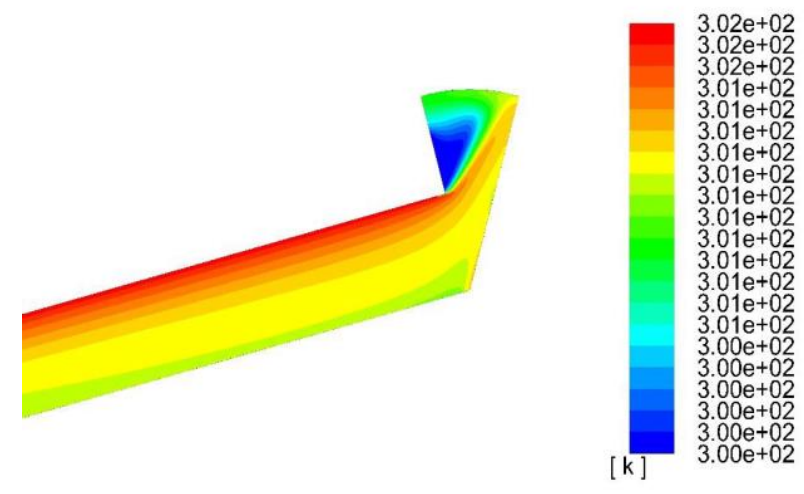

(c) Temperature field at 15:00

Figure 5. Winter air temperature fields at the end of the channel

In Figure 9(a) and (b) it is possible to see that the along the cross-sections of the channel, the differences between the values are not as evident as for the central line, in fact the range of values, near the upper layer of the channel, in summer case is equal to $0.30-0.34 \mathrm{~m} / \mathrm{s}$ while it is $0.43-0.50 \mathrm{~m} / \mathrm{s}$ in winter configuration.

For better understand the behavior of the analyzed ventilated channel with an inclination of the roof equal to $15^{\circ}$ respect to the horizontal plane, a comparison, Figures 10-14, with a configuration having same materials and properties but with different inclination of the channel, specifically equal to $30^{\circ}[15]$, was made. Due to brevity, in this paper are reported only the evaluations made at 12:00. 
Table 4. Thermophysical characteristics of the material in the ventilated roof

\begin{tabular}{|c|c|c|c|c|c|}
\hline No. of layer & Description of layer & Thickness [m] & $\rho\left[\mathrm{kg} \mathrm{m}^{-3}\right]$ & cp $\left[\mathrm{J} \mathrm{Kg}^{-1} \mathrm{~K}^{-1}\right]$ & $\lambda\left[\mathbf{W} \mathbf{m}^{-1} \mathbf{K}^{-1}\right]$ \\
\hline 1 & Brick tiles & 0.035 & 1920 & 835 & 0.72 \\
\hline 2 & Wooden planking & 0.01 & 510 & 1380 & 0.12 \\
\hline 3 & Air (ventilation layer) & 0.1 & 1177 & 1600 & 0.026 \\
\hline 4 & Cement mortar & 0.015 & 1860 & 780 & 0.72 \\
\hline 5 & Brick and concrete floor slab & 0.3 & 1600 & 880 & 0.81 \\
\hline 6 & Lime mortar and cement plastering & 0.015 & 1800 & 1000 & 0.90 \\
\hline
\end{tabular}

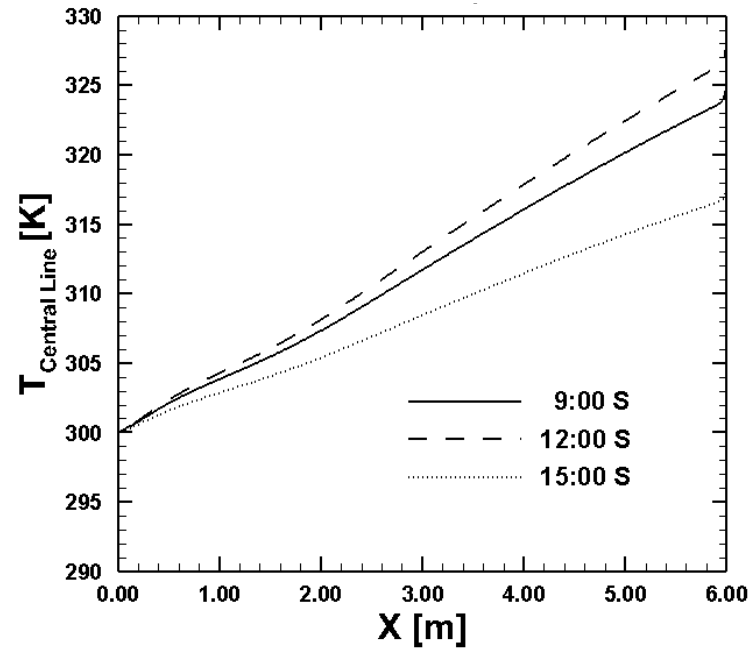

(a) Summer configuration

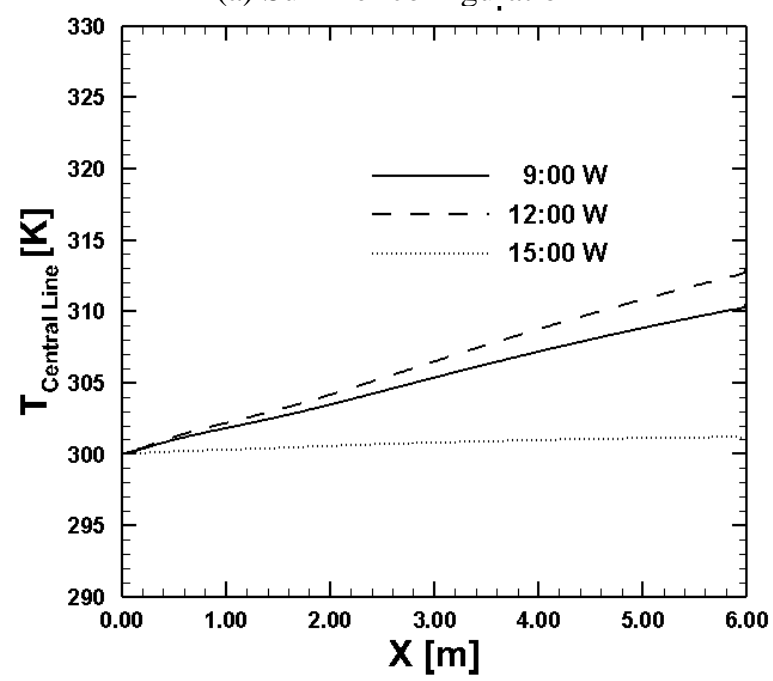

(b) Winter configuration

Figure 6. Temperature profiles along central line

By the comparison among the velocity profiles made along the central line, in Figure 10, it is possible to note that in both summer and winter configuration, due to the higher inclination of the channel, in the case of $\theta=30^{\circ}$ the velocity reaches higher values of it. As with the central line, the profiles of the velocity along the transversal sections also show high values of the velocity in the configuration with the inclination of the roof equal to $30^{\circ}$ respect to the $15^{\circ}$ inclined channel. In fact, for example, at $1 \mathrm{~m}$ from the inlet section of the $30^{\circ}$ inclined channel, the velocity values are equal to $0.50 \mathrm{~m} / \mathrm{s}$ and $0.70 \mathrm{~m} / \mathrm{s}$ during winter and summer case, respectively, while at the same distance but for the channel inclined of $15^{\circ}$ respect to the horizontal plane, the values of the velocity are equal to 0.31 $\mathrm{m} / \mathrm{s}$ and to $0.44 \mathrm{~m} / \mathrm{s}$ during winter and summer case, respectively.

Like for the velocity also for the temperature along the central line a comparison was made, in Figure 11, and in both considered case (summer and winter) temperatures increase as the distance from the inlet section of the channel, but for the roof with less slope the values are higher respect the other case. In particular, in the middle of the channel, during the summer the temperature is equal to $309 \mathrm{~K}$ for the inclination of the roof equal to $30^{\circ}$ and it is equal to $313 \mathrm{~K}$ in the $15^{\circ}$ case, while in winter the values are $306 \mathrm{~K}$ and $307 \mathrm{~K}$ for inclination equal to $30^{\circ}$ and $15^{\circ}$, respectively.

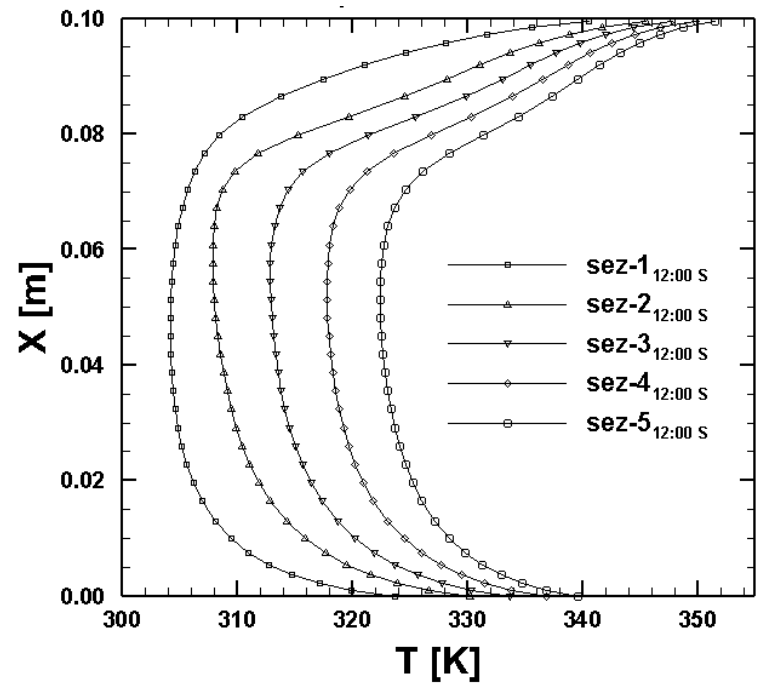

(a) Summer configuration

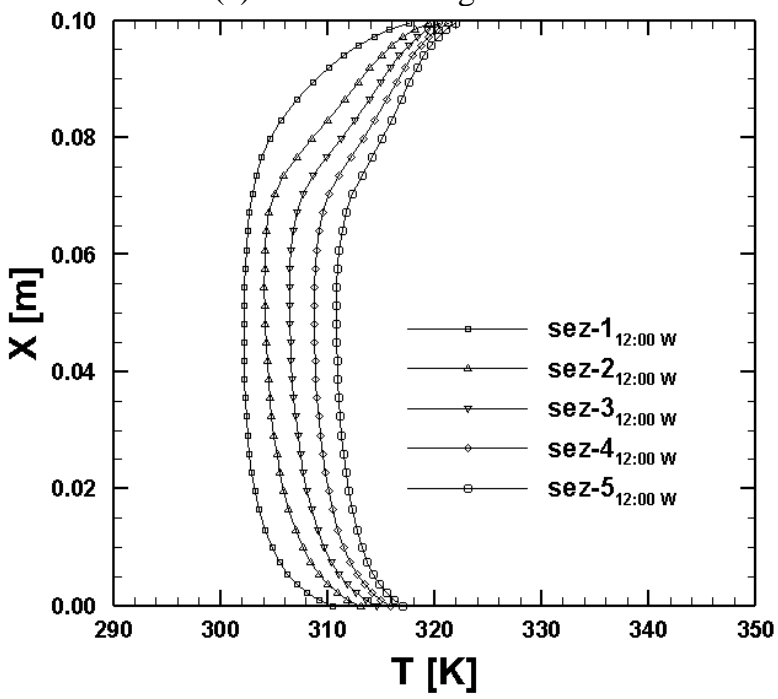

(b) Winter configuration

Figure 7. Temperature profiles along transversal sections at 12:00

Another comparison is made between the different temperature achieved by the tiles of the ventilated channel at the 12:00, in Figure 12. The results show that the temperature on the upper surface of the channel reach greater values due 
the higher thermal flow resulting from radiation; specifically, result for the inclination of the roof equal to $30^{\circ}$ a value of temperature equal to $324 \mathrm{~K}$ in winter and to $345 \mathrm{~K}$ in summer, while for the roof inclined of $15^{\circ}$ respect to the plane the temperature of the tiles is $322 \mathrm{~K}$ in winter and $351 \mathrm{~K}$ during the summer. So, in the summer case at 12:00, the values of the temperature of tiles are higher in the case of $15^{\circ}$ while at 15:00 the opposite happens.

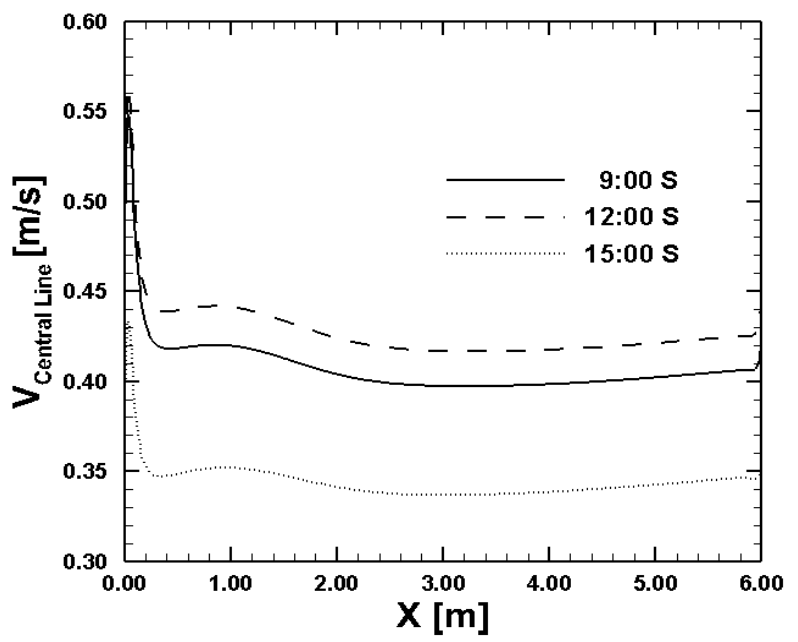

(a) Summer configuration

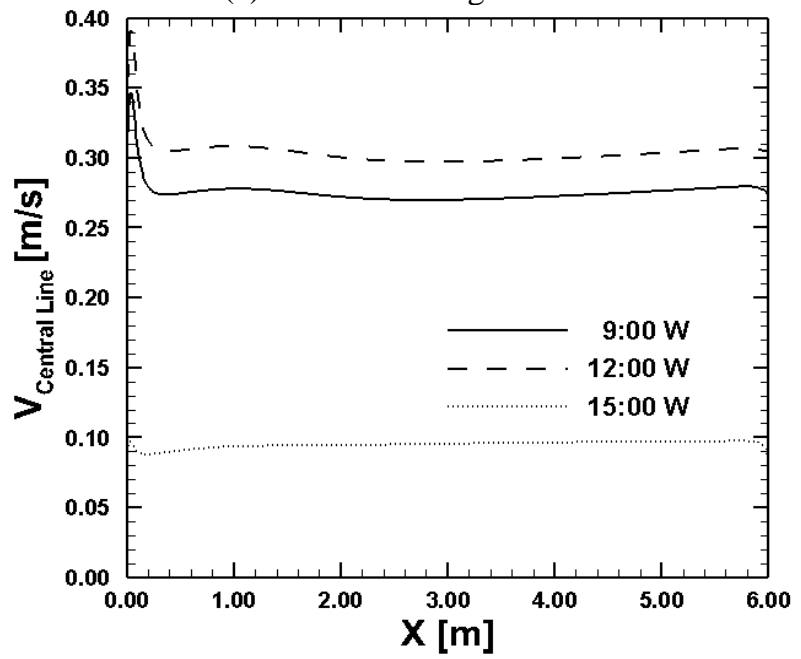

(b) Winter configuration

Figure 8. Velocity profiles along central line

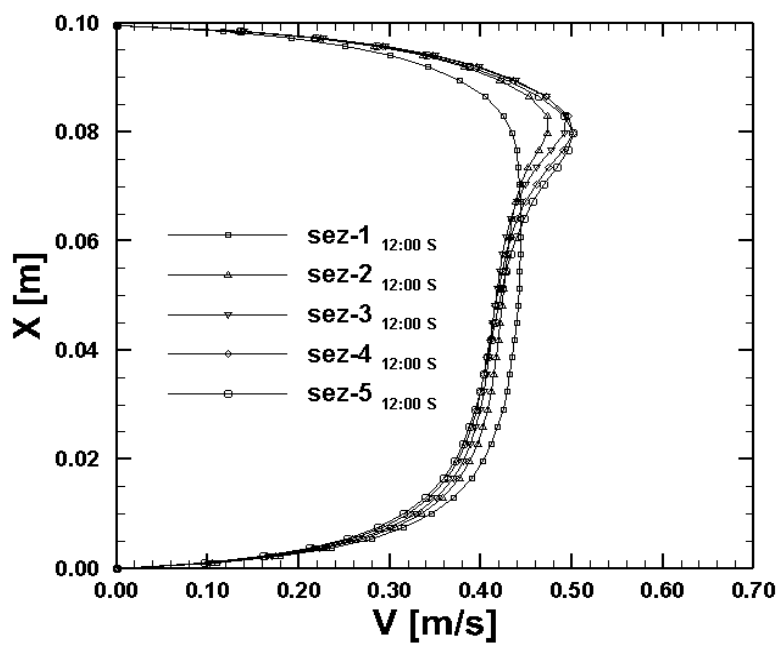

(a) Summer configuration

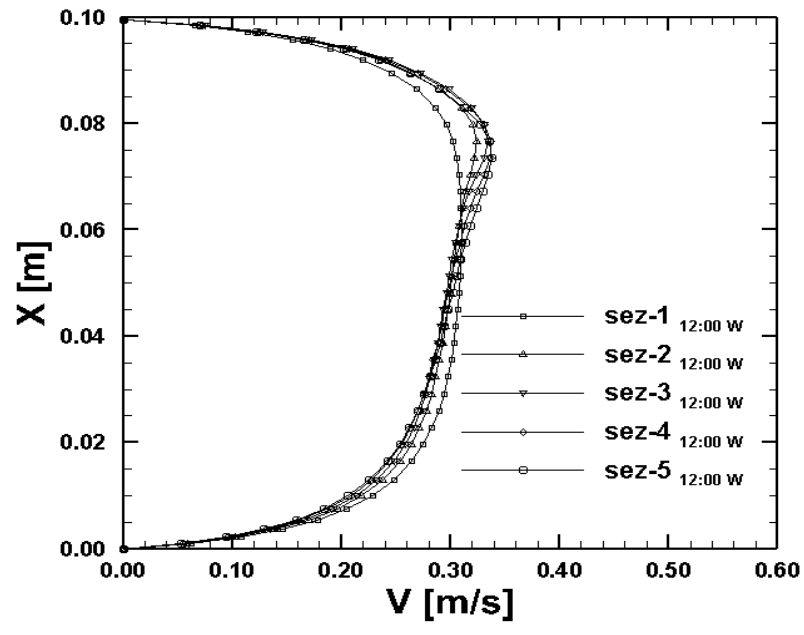

(b) Winter configuration

Figure 9. Velocity profiles along transversal sections at $12: 00$

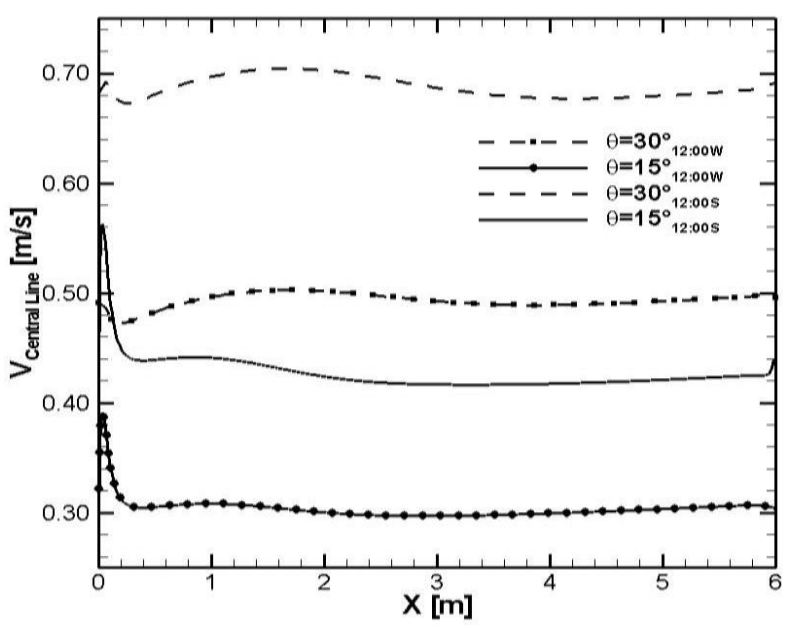

Figure 10. Comparison of velocity profiles along central line at 12:00

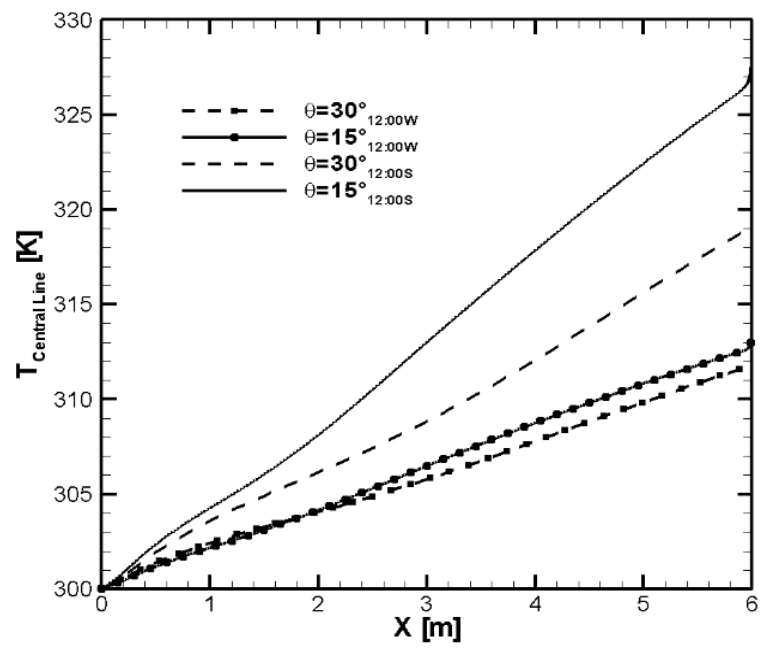

Figure 11. Comparison of temperature profiles along central line at 12:00

During the winter, instead, at 9:00 a.m. the temperature reached in the $15^{\circ}$ inclined roof are higher than in the $30^{\circ}$ case, vice versa at 12:00 and 15:00.

From the analyzes carried out, the values of the mass flow 
rate of air inside the channel were obtained (Table 5).

This table show that, in agreement with the speed values calculated in the center line and along the cross sections for each geometric configuration, both in summer and in winter cases, the value of the mass flow rate that crosses the channel is higher in the roof with greater inclination.

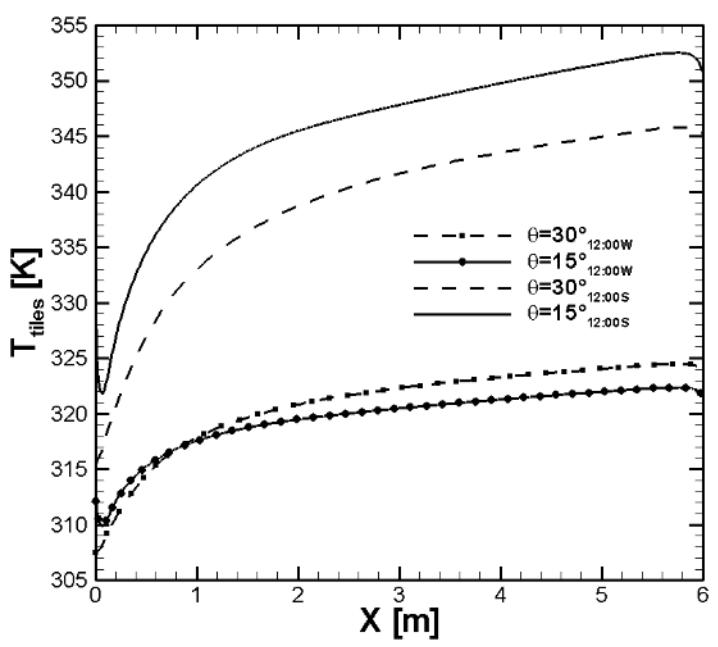

Figure 12. Comparison of temperature profiles of the tiles during summer and winter conditions at 12:00

Table 5. Mass flow rate during summer and winter

\begin{tabular}{ccccc}
\hline & \multicolumn{2}{c}{$\dot{\mathbf{m}}_{\text {summer }}[\mathrm{kg} / \mathbf{s}]$} & \multicolumn{2}{c}{$\dot{\mathbf{m}}_{\text {winter }}[\mathrm{kg} / \mathbf{s}]$} \\
\hline Time $[\mathbf{h}]$ & $\boldsymbol{\theta} \mathbf{1 5}^{\circ}$ & $\boldsymbol{\theta}=\mathbf{3 0}^{\circ}$ & $\boldsymbol{\theta =} \mathbf{1 5}^{\circ}$ & $\boldsymbol{\theta}=\mathbf{3 0}^{\circ}$ \\
\hline $9: 00$ & 0.044 & 0.063 & 0.028 & 0.035 \\
\hline $12: 00$ & 0.046 & 0.074 & 0.031 & 0.052 \\
\hline $15: 00$ & 0.036 & 0.065 & 0.009 & 0.38 \\
\hline
\end{tabular}

These results can be observed in the pressure profiles of the air inside the ventilated channel in both configurations, Figures 13 and 14, evaluated. This pressure is lower than the atmospheric pressure thus the circulation of the air inside the cavity increases and so the heat transfer from inside to outside of it.

This air depression is more higher during the summer but, considering the same climatic conditions, the inclination of the roof made a substantial difference on the quantity of the air mass flow inside the channel. In fact, for example as reported in the Table 5, at 12:00 in the summer case the mass flow rate of the roof inclined of $15^{\circ}$ is equal to $0.046 \mathrm{~kg} / \mathrm{s}$ while for the channel inclined of $30^{\circ}$ it is equal to $0.074 \mathrm{~kg} / \mathrm{s}$.

\section{CONCLUSIONS}

A numerical examination was realized to know the thermal behavior of a prototypal ventilated roof for residential use under variable solar energy which simulate summer and winter conditions. The system is composed by a single side of the roof, due to its geometrical and thermal symmetry, and it consists of a ventilated channel on which bottom surface a constant value of temperature is applied to simulate optimal indoor condition in summer and winter periods, and on the top wall a heat flux was applied to reproduce solar radiation operating at different hours on typical summer and winter days. Then a comparison with a different inclination of the same model was made.

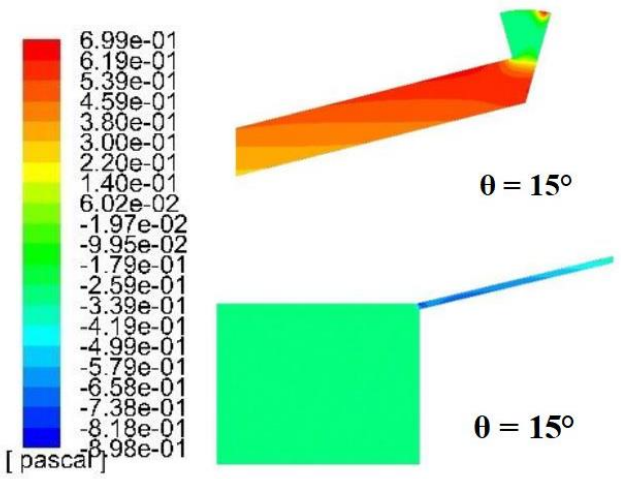

(a) Summer configuration, channel inclined of $15^{\circ}$

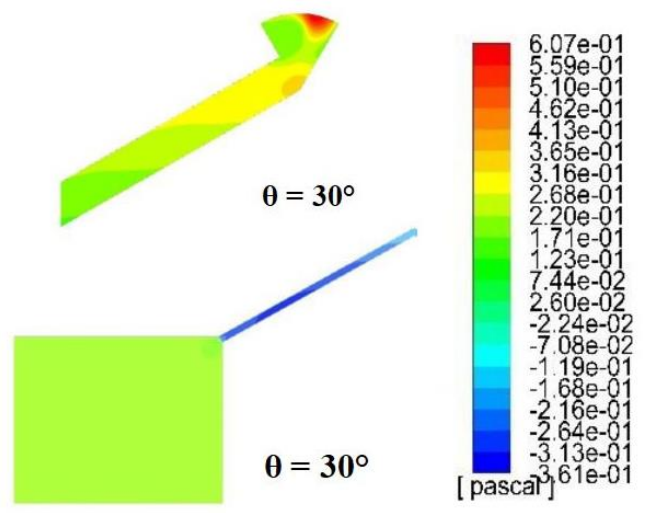

(b) Summer configuration, channel inclined of $30^{\circ}$

Figure 13. Summer pressure fields (a) $15^{\circ}$ and (b) $30^{\circ}$.

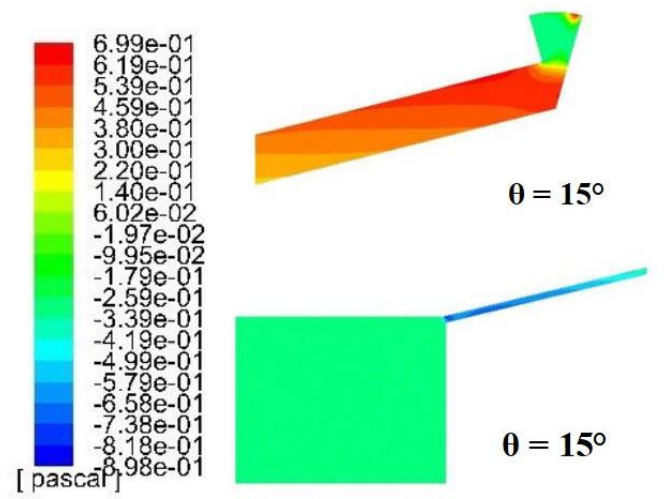

(a) Winter configuration, channel inclined of $15^{\circ}$

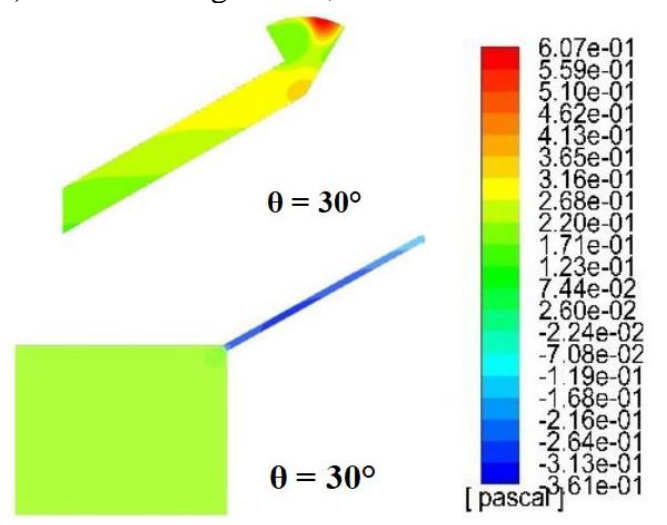

(b) Winter configuration, channel inclined of $30^{\circ}$

Figure 14. Winter pressure fields for (a) $15^{\circ}$ and (b) $30^{\circ}$

Analyzing the thermal behaviors, the study has revealed that the temperature measured along the center line of the channel and on the tiles growths a lot when the distance from the inlet 
section increases, moreover the highest values are reached at 12:00 when the high value of the solar irradiation generates an elevated quantity of the heat flux. Thanks to the comparisons made, it is evident that during the summer in the channel with an inclination of $15^{\circ}$ higher temperature values are reached compared to the roof with an inclination equal to $30^{\circ}$, while in the winter case the difference of the temperature between the two analyzed configuration is not so evident.

The velocity increases in the channel due to the air heating, specifically in the hottest hours, with values equal to $0.6-0.7$ $\mathrm{m} / \mathrm{s}$ that are almost constant. By the comparison of the two analyzed configurations, the results show higher velocities in the channel inclined of $30^{\circ}$.

Thus, the results of the numerical simulation carried out show the importance of the ventilated cavity to removes the heat inside the channel, especially in summer regime because the high thermal flow generates an optimal air-convective condition into the cavity (Table 5); in winter, the effect of the ventilated layer is very important to reach optimal thermal and hygrometric conditions. This is important, for example, to allow the melting of the snow and to avoid the problems related to the water condensation for the materials.

\section{ACKNOWLEDGMENT}

LC thanks the Regione Campania for the PhD fellowship "Impiego dei materiali a cambiamento di fase per il recupero e l'accumulo di energia termica negli edifici sostenibili (Phase change materials in recovery and thermal energy storage in sustainable buildings)" in the frame of Dottorati di Ricerca con Caratterizzazione Industriale, funded with P.O.R. Campania FSE 2014/2020 Asse III - Obiettivo specifico 14 Azione 10.4.5.

\section{REFERENCES}

[1] Manca, O., Mangiacapra, A., Marino, S., Nardini, S. (2014). Numerical investigation on thermal behaviors of an inclined ventilated roof. 12th Biennial Conference on Engineering Systems Design and Analysis ESDA2014, Copenhagen,

Denmark. https://doi.org/10.1115/ESDA2014-20391

[2] Gagliano, A., Patania, F., Nocera, F., Ferlito, A., Galesi. A. (2012). Thermal performance of ventilated roofs during summer period. Energy and Buildings, 49: 611618. https://doi.org/10.1016/j.enbuild.2012.03.007

[3] Dong, L., Zheng, Y., Liu, C., Qi, H., Liu, X. (2016). Numerical analysis on thermal performance of naturally ventilated roofs with different influencing parameters. Sustainable Cities and Society, 22: 86-93. https://doi.org/10.1016/j.scs.2016.02.004

[4] Bianco, V., Diana, A., Manca, O., Nardini, S. (2016). Thermal behavior evaluation of ventilated roof under variable solar radiation. International Journal of Heat and Technology, 34(2):

S346-S350. https://doi.org/10.18280/ijht.34S222

[5] Bortoloni, M., Bottarelli, M., Piva, S. (2017). Summer thermal performance of ventilated roofs with tiled coverings. Journal of Physics: Conference Series, 796: 110. https://doi.org/10.1088/1742-6596/796/1/012023

[6] Di Giuseppe, E., Sabbatini, S., Cozzolino, N., Stipa, P., D’Orazio, M. (2019). Optical properties of traditional clay tiles for ventilated roofs and implication on roof thermal performance. Journal of Building Physics, 42(4): 484-505. https://doi.org/10.1177/1744259118772265

[7] Leccese, F., Salvadori, G., Barlit, M. (2019). Ventilated flat roofs: A simplified model to assess their hygrothermal behavior. Journal of Building Engineering 22: 12-21. https://doi.org/10.1016/j.jobe.2018.11.009

[8] Ferrari, C., Muscio, A. (2019). Ventilated pitched roof with forced ventilation and flow homogenizer device: Testing and performance assessment. Journal of Physics: Conference $\quad$ Series, 1224 : 1-8. https://doi.org/10.1088/1742-6596/1224/1/012027

[9] Bunkholt, N.S., Säwén, T., Stockhaus, M., Kvande, T., Gullbrekken, L., Wahlgren, P., Lohne, J. (2020). Experimental study of thermal buoyancy in the cavity of $\begin{array}{llll}\text { ventilated } & \text { roofs. } & \text { Buildings, }\end{array}$ https://doi.org/10.3390/buildings 10010008

[10] Vaishnani, Y., Ali, S.N., Joshi, A., Rakshit, D., Wang, F. (2020). Thermal performance analysis of a naturally ventilated system using PMV models for different roof inclinations in composite climatic Conditions. Journal of the Brazilian Society of Mechanical Sciences and Engineering, 42. https://doi.org/10.1007/s40430-0202219-4

[11] Launder, B.E., Spalding, D.B. (1974). The numerical computation of turbulent flow. Computer Methods Applied Mechanics and Engineering, 3: 269-289. https://doi.org/10.1016/0045-7825(74)90029-2

[12] ANSYS-Fluent Inc. Ansys-Fluent.

[13] https://re.jrc.ec.europa.eu/pvg_tools/en/tools.html.

[14] Fluent-Inc. Gambit 2.4 Modeling Guide ed. 2007.

[15] Bianco, V., Diana, A., Manca, O., Nardini, S. (2018). Numerical investigation of an inclined rectangular cavity for ventilated roofs applications. Thermal Science and Engineering Progress, 6: 426-435

\section{NOMENCLATURE}

$\mathrm{b}$

channel width, $\mathrm{m}$

h hipped roof height, $\mathrm{m}$

L channel length, $\mathrm{m}$

$\mathrm{L}_{\mathrm{x}}, \mathrm{L}_{\mathrm{y}} \quad$ inlet reservoir dimensions, $\mathrm{m}$

$\mathrm{q}_{\mathrm{s}} \quad$ heat flux in summer, $\mathrm{w} / \mathrm{m}^{2}$

$\mathrm{q}_{\mathrm{w}} \quad$ heat flux in winter, $\mathrm{w} / \mathrm{m}^{2}$

$\mathrm{T} \quad$ operative temperature, $\mathrm{k}$

$\mathrm{T}_{\mathrm{s}} \quad$ temperature in summer regime, $\mathrm{k}$

$\mathrm{T}_{\mathrm{w}} \quad$ temperature in winter regime, $\mathrm{k}$

$\mathrm{T}_{\text {avg }}$ average value of the temperature in the exit section of the channel, $\mathrm{K}$

$\mathrm{T}_{\text {havg }} \quad$ average value of the temperature on the top wall of the ventilated channel, $\mathrm{K}$

$V_{\text {avg }}$ average value of the velocity in the ventilated channel, $[\mathrm{m} / \mathrm{s}]$

$\mathrm{v}_{\max } \quad$ maximum value of the velocity in the ventilated channel, $[\mathrm{m} / \mathrm{s}]$

X, Y ,Z Cartesian coordinates

\section{Greek symbols}

$\theta \quad$ roof inclination, ${ }^{\circ}$

$\mathrm{k} \quad$ kinetic energy of turbulence

$\varepsilon \quad$ turbulent kinetic energy dissipation 